\title{
Soil mites inhabiting chamomile and marigold plants under two different cultivations at Fayoum governorate
}

\author{
Zaki, A. Y. and Reham I. A. Abo-Shnaf \\ Vegetable and Aromatic Plant Mites Department, Plant Protection Research Institute, Agricultural Research Centre, \\ Dokii, Giza, Egypt. E-mail: ayzaki1975@yahoo.com; riamaboshnaf@yahoo.com
}

\begin{abstract}
An experiment was conducted in two localities at Fayoum governorate to observe soil mites inhabiting two important medicinal and aromatic plants namely; chamomile(Matricaria chamomilla L.) and marigold (Calendula officinalis L.). Samples were collected biweekly from December 2016 to April 2017. After mite samples extraction, specimens were mounted in Hoyer's medium on microscope slides for later examination. The results revealed the occurrence of 43 species from 36 genera and 24 families. This included four species from both families, Cunaxidae and Rhodacaridae which were recorded for the first time in Egypt. Total soil mites were 1466individuals, from which 793individuals in chamomile and 673 individuals marigold. The total number of mites collected from each cultivated system reached respectively $484 \&$ 309 individualsin organic and conventional chamomile and $449 \& 224$ individualsin organic and conventional marigold. From 24 families: $10 \& 7$ families were not found in organic and conventional chamomile, and $5 \& 9$ families in organic and conventional marigold. The highest numbers presented in the families Euopodidae about 175 individuals (in organic chamomile), Acaridae about 135 \& 110 individuals (in conventional chamomile \& marigold), 130 individuals (in organic marigold). The highest number of soil mites was presented by the families Oribatulidae and Eupodidae in chamomile, while in marigold were the families Acaridae and Oribatulidae. Shannon-Wiener "H" Indexindicated that organic marigold reached the highest value (2.31) of 30 species from 19 families, while Simpson Index, demonstrated that it recorded the lowest number of dominant species. For speciessimilarity, the community of organic almost resembled that of conventionalone by $50 \%$ in chamomile and $51.06 \%$ in marigold.
\end{abstract}

Key words: Fauna, Biodiversity, Organic, Conventional, Medicinal and aromatic plants, Egypt.

\section{INTRODUCTION}

Chamomile and marigold plants are considered the most dominant medicinal and aromatic plants cultivated at Fayoum governorate, where this region is considered the highest productiviy for those crops in Egypt. Cultivated area, yield and production at Fayoum governorate reached respectively (7234 \& 220 fed.), (0.875 \& 15.482 ton/fed.) and (6330 \& 3406 ton) for chamomile and marigold (Anonymous, 2016).

Chamomile (Matricaria chamomilla L.) is a highly favored and much used medicinal plant infolk and traditional medicine. Its multitherapeutic, cosmetic, and nutritional values have been established through years of traditional and scientific use and research (Singh et al., 2011). In addition to pharmaceutical uses, the oil is extensively used in perfumery, cosmetics, aromatherapy, and food industry (Lal et al., 1993).

Marigold (Calendula officinalis L.) has been traditionally used in the treatment of various skin tumors, dermatological lesions, ulcers, swellings and nervous disorders as well as almost 200 cosmetic formulations, i.e., creams, lotions, shampoos (Arora et al., 2013).

Organic farming shows significant improvements for functions such as: reduction in soil erosion on arable land (Siegrist et al., 1998), decomposition of dung in pastures (Hutton \& Giller, 2003), natural pest reduction in soil (Klingen et al., 2002) and on crops (Zehnder et al., 2007; Crowder et al., 2010). It improves biodiversity and increases occurrence of beneficial organisms (Klingen et al., 2002; Rizk, 2015).Organic practices are designed to promote beneficial biotic processes; organically managed agro-ecosystems comprise a suite of community and ecosystem characteristics that may compensate for synthetic chemical inputs (Lampkin, 1990).Organic amendments such as manure, compost, biosolids, and humic substances provide a direct source of carbon (C) for soil organisms as well as an indirect (C) source via increased plant growth and plant residue returns (Bünemann et al., 2006).On the other hand, chemical fertilizers can dramatically influence the balance of nutritional elements in plants, and it is likely that their excessive use will create nutrient imbalances, which in turn, reduce resistance to insect pests (Altieri \& Nicholls, 2003).

Application of compost to improve soil structure, fertility and consequently development and productivity of medicinal plants were studied in several cases (Raey \& Alami-Milani, 2014). It is argued that organic systems are more diverse, and therefore more stable, resulting in lower incidences of pest and disease problems, and increased biodiversity (Lampkin, 1990; Paoletti et al., 1992). 
Soil mites are abundant organisms that are sensitive to soil perturbations in agricultural practices and their numbers and diversity often get reduced affecting their ecosystem services (Minor \& Cianciolo, 2007). Several genera of soil mites are considered good bio-indicators of habitat and soil conditions (Behan-Pelletier, 1999).

Therefore, the present study was aimed to evaluate the influence of organic and conventional cultivation systems on soil mites inhabiting two medicinal and aromatic plants at Fayoun governorate, Egypt.

\section{MATERIALS AND METHODS}

\section{a.Studied area:}

Two medicinal and aromatic plants, Chamomile; Matricaria chamomilla L. and Marigold; Calendula officinalis L. (Asteraceae), in two localities at Fayoum governorate; Abu Kasah $\left(30^{\circ} 42^{\prime} \mathrm{E}, 2^{\circ} 22^{\prime}\right.$ $\mathrm{N})$ as a conventional cultivation system and $\mathrm{Abu}$ Junshu ( $\left.30^{\circ} 40^{\prime} \mathrm{E}, 29^{\circ} 21^{\prime} \mathrm{N}\right)$ as an organic cultivation systemwere chosen for this study. Each crop cultivated as organic or conventional were in equal area of about $1400 \mathrm{~m}^{2}$. All agricultural practices were carried out as requirements for the cultivation system and cultivated plants. The conventional plots were treated with inorganic fertilizers and sprayed with pesticides where appropriate, while the organic plots were fertilized with compost and no pesticides used.

\section{b. Samples collection:}

Samples of debris, litters and soil were collected every two weeks from December 2016 to April 2017 in the two mentioned localities. Mites were extracted from samples in modified Tullgren funnels, mounted in Hoyer's medium on microscope slides for later examination. After a cover slide had been placed, the slides were placed on a hot plate for two weeks. Name of region, host plant, collecting date were written on labels and stuck on the slides. Specimens of phytophagous, predacious and other mites of miscellaneous feeding habits were examined under Leica Micro Star IV and phase contrast (Olympus, BHA) microscopes for species identification, using the world taxonomic literature. Collections were done by the first author of this paper.

\section{c- Species diversity}

It was measured by diversity index that reflected the number of species (richness) in the samples. Two common indices were computed, Shannon-Wiener index "H" and Simpson index "S". They were calculated as described by Ludwig and Reynolds (1988). $\mathrm{H}^{\prime}=-\Sigma(\mathrm{ni} / \mathrm{n}) \ln (\mathrm{ni} / \mathrm{n})$ and $\mathrm{S}=\Sigma(\mathrm{ni} / \mathrm{n}) 2$ where ni is the number of individuals belonging to the $i^{\text {th }}$ of "S" taxa in the sample and " $n$ " is the total number of individuals in the sample. " $\mathrm{H}$ " is more sensitive to changes in number of species and diversity, while "S" is a dominance index gives more weight to common or dominant species (Ludwig \& Reynolds, 1988); it highly suggests that the two individuals drawn at random from the population belong to the same species. If the result is high then the probability of both individuals belonging to the same species is high, and as a result the diversity of the community samples might be low.

\section{d. Sørensen quotient of similarity}

Sørensen's quotient of similarity (Sørensen, 1948) was used to determine the similarities of mite species composition among the communities, as: $\mathrm{QS}=2 \mathrm{C} / \mathrm{A}$ $+\mathrm{B}$. Where $\mathrm{A}$ and $\mathrm{B}$ are the number of species in samples A and B, respectively; $C$ is the number of species shared by the two samples; QS is the quotient of similarity and ranges from $0-1$. [A = Organic management, $\mathrm{B}=$ conventional management $]$.

\section{RESULTS AND DISCUSSION}

\section{Mite species richness}

Forty-three species belonging to 36 genera and 24 families from one order (Mesostigmata), two suborders

(Prostigmata and Oribarida) and one Cohort (Astigm atina) are identified, including four species from two families firstly recorded; Coleoscirus simplex (Ewing), Cunaxa lehmanae Smileyand Cunaxa womersleyi Baker \& Hoffmann (family: Cunaxidae), and Rhodacarellus iraninensis Castilho, Jalaeian \&Moraes (family Rhodacaridae) (Table 1). Similarly to the results of this study, when plant was tomato, Abo-Shnafet al. (2016)recorded 33 species of 27 genera and 21 families from Astigmata, Prostigmata, Mesostigmata and Oribatida on plants at the same governorate.Also, Zhiping et al. (2011)mentioned a total of ten families of Prostigmata, eight families of Mesostigmata, two families of Astigmata, and 15 families of Oribatida concluded 17 genera were identified under organic and chemical fertilizer treatments.

The total mites were 1466 individuals; highest numbers was 793 individuals in chamomile and lowestone in marigold.The total number of mites collected from each cultivated system reached respectively $484 \& 309$ individualsin organic and conventional chamomile and $449 \& 224$ individualsin organic and conventional marigold.

\section{Rank abundance of mite families:}

The collected mites were presented by 24 families (Table 1). There are two families constitute the majority of the total collected mite species i.e: 
Table (1): Number of soil mites in organic (or) and conventional (Conv.) cultivation systems

\begin{tabular}{|c|c|c|c|c|c|}
\hline \multirow{2}{*}{ Family } & \multirow{2}{*}{ Mite taxa } & \multicolumn{2}{|c|}{ Chamomile } & \multicolumn{2}{|c|}{ Marigold } \\
\hline & & Or. & Conv. & Or. & Conv. \\
\hline Acaridae Leach & Tyrophagus putrescentiae (Schrank) & 3 & 135 & 70 & 110 \\
\hline \multirow{2}{*}{ Ameroseiidae Evans } & Kleemania wahabi Ibrahim \& Abdel-Samed & 1 & 1 & 2 & \\
\hline & Sertitympanum zaheri (El-Badry, Nasr \& Hafez) & & & 2 & 11 \\
\hline \multirow{2}{*}{ Ascidae } & Arctoseius bilinear Nasr & & 47 & & 11 \\
\hline & Gamasellodes bicolor (Berlese) & & 10 & & 3 \\
\hline Bdellidae Duges & Neomolgus aegyptiacus Soliman \& Mohamed & & 1 & 2 & 1 \\
\hline Blattisociidae & Lasioseius aff. africanus (Nasr) & & & 1 & \\
\hline \multirow{3}{*}{ Caligonellidae Grandjean } & Caligonella humilis (Koch) & & & 2 & \\
\hline & Molothrognathus platelettus Soliman \& Gomaa & & 1 & & \\
\hline & Neognathus oteifi Soliman \& Gomaa & & & 2 & \\
\hline Cheyletidae Leach & Cheyletus malaccensis Oudemans & & 3 & 19 & 1 \\
\hline \multirow{4}{*}{ Cunaxidae Thor } & Coleoscirus simplex (Ewing)* & 6 & & 5 & \\
\hline & Cunaxa lehmanae Smiley* & 4 & & 2 & \\
\hline & C. setirostris (Hermann) & 4 & & 2 & \\
\hline & C. womersleyi Baker \& Hoffmann* & & & 1 & \\
\hline \multirow{2}{*}{ Eupodidae Koch } & Eupodes temperatus Shiba & & & 7 & \\
\hline & E. voxencollinus Sig Thor & 175 & 13 & 14 & 12 \\
\hline \multirow{7}{*}{ Laelapidae Berlese } & Androlaelaps aegypticus Hafez, El-Badry \& Nasr & & & 1 & \\
\hline & A. casalis (Berlese) & 1 & & 1 & 2 \\
\hline & Gaeolaelaps bregetovae (Shereef \& Afifi) & & 2 & & \\
\hline & G. orientalis (Hafez, El-Badry \& Nasr) & & & 1 & \\
\hline & Hypoaspis petrovae Shereef \& Afifi & 2 & & & \\
\hline & H. zachvatkinae Shereef \& Afifi & 10 & 1 & 5 & \\
\hline & Ololaelaps bregetovae Shereef \& Soliman & 80 & 4 & 21 & 1 \\
\hline Macrochelidae Vitzthum & Macrocheles merdarius (Berlese) & 2 & & 11 & 18 \\
\hline \multirow{2}{*}{ Melicharidae } & Proctolaelaps aegyptiacus Nasr & 6 & & 3 & \\
\hline & P. holoventris Moraes, Britto, Mineiro \& Halliday & & & 2 & 1 \\
\hline \multirow{2}{*}{ Ologamasidae Ryke } & Gamasiphis pulchellus (Berlese) & 14 & & & \\
\hline & Sessiluncus aegypticus Nasr \& Afifi & 1 & & & \\
\hline Oppiidae Grandjean & Oppia bayoumii Shereef \& Zaher & 41 & 4 & 21 & \\
\hline \multirow{2}{*}{ Oribatulidae Thor } & Scheloribates zaheri Yousef \& Nasr & 108 & 49 & 130 & 13 \\
\hline & Zygoribatula sayedi El-Badry \& Nasr & & 1 & & \\
\hline \multirow{2}{*}{ Pachylaelapidae Berlese } & Pachylaelaps aegypticus Hafez \& Nasr & & 14 & 92 & 20 \\
\hline & Pachylaelaps reticulates $\mathrm{Hafez} \&$ Nasr & & 1 & & \\
\hline Parasitidae Oudemans & Parasitus consanguineus Oudemans \& Voigts & 8 & 15 & 1 & \\
\hline Phytoseiidae Berlese & Neoseiulus barkeri Hughes & 3 & 3 & 2 & 15 \\
\hline Raphignathidae Kramer & Raphignathus niloticus Rakha \& Mohamed & & 1 & 1 & \\
\hline \multirow{2}{*}{ Rhodacaridae } & Multidentorhodacarus aegypticus Abo-Shnaf, Castilho \& Moraes & 14 & & 15 & \\
\hline & Rhodacarellus iraninensis Castilho, Jalaeian \& Moraes* & & 1 & & 1 \\
\hline Siteroptidae Mahunka & Siteroptes manuri Soliman \& Kandeel & & 1 & & \\
\hline Stigmaeidae Oudemans & Stigmaeus africanus Soliman \& Gomaa & & & 11 & \\
\hline Tetranychidae Donnadieu & Petrobia latens (Müller) & 1 & 1 & & 1 \\
\hline Tydeidae Kramer & Tydeus costensis Baker & & & & 3 \\
\hline Total & & 484 & 309 & 449 & 224 \\
\hline
\end{tabular}

Table (2): Estimation of Shannon-Wiener and Simpson Indices of soil mites' diversity in chamomile and marigold (organic and conventional cultivation system)

\begin{tabular}{ccc|cc}
\hline & \multicolumn{2}{c|}{ Chamomile } & \multicolumn{2}{c}{ Marigold } \\
\cline { 2 - 5 } & Organic & conventional & Organic & conventional \\
\hline Shannon-Wiener Index & 1.91 & 1.86 & 2.31 & 1.85 \\
\hline Simpson Index & 0.22 & 0.25 & 0.16 & 0.27 \\
\hline
\end{tabular}


Acaridae and Oribatulidae. The greatest number of collected individuals presented by the Family Acaridae (318 individuals) and ranked the first (21.69\%), followed by the Family Oribatulidae (301 individuals) which ranked the second $(20.53 \%)$. The highest numbers of collected mites were presented by the families Euopodidae 175individuals (in organic chamomile), Acaridae $135 \& 110$ individuals (in conventional chamomile \& marigold), Oribatulidae 130 individuals (in organic marigold). Also, the highest numbers of soil mites were presented by the families Oribatulidae (158 individuals) and Eupodidae (188 individuals) in chamomile cultivation system;while in marigold were the families Acaridae (180 individuals) and Oribatulidae (143 individuals).

Also, Table (1) shows that in organic chamomile, the families Ascidae, Bdellidae, Blattisociidae, Caligonellidae, Cheylitidae, Pachylaelapidae, Raphignathidae, Siteroptidae, Stigmaeidae, and Tydeidae not distinguished. In conventional chamomile the families Blattisociidae, Cunaxidae, Macrochelidae, Melicharidae, Ologamasidae, Stigmaeidae, and Tydeidae are not distinguished. In organic marigold families Ascidae, Ologamasidae, Siteroptidae, Tetranychidae, and Tydeidae arenot distinguished. In conventional marigold families Blattisociidae, Caligonellidae, Cunaxidae, Ologamasidae, Opiidae, Parasitidae, Raphignathidae, Siteroptidaeand Stigmaeidae not distinguished.

Zhiping .et al. (2011) mentioned that mites comprised $19.6 \%$ Acaridae, $18.8 \%$ Protoribatidae (Transoribates agricola), 7.5\% Microdispidae 7.1\% Epilohmanniidae (Epilohmannia sp.), 5.1\% Scutacaridae, 3.8\% Tectocepheidae (Tectocepheus velatus), 3.5\% Scheloribatidae (Scheloribates sp.), 3.0\% Laelapidae, 2.8\% Uropodidae, 2.4\% Ascidae and $2.1 \%$ Ceratozetidae (Ceratozetes sp.) under organic and chemical fertilizer treatments.

\section{Species diversity}

Table (2) compared the biodiversity of collected mites in organic and conventional cultivations by using Shannon-Wiener "H" and Simpson "S" Indices of diversity.

The mite richness varied in both cultivations, as mites inhabiting organic cultivation were the highest as recorded 484in chamomile and 449 individuals.in marigold,compared with conventional cultivation (309 in chamomile and 224 individualsin marigold).

According to Shannon-Wiener "H" Index, the organicmarigoldrecorded the highest value (2.31) of 30 species and 19 families, this indicated that organic marigold plants had a higher diversity index and theothers had a lower one. Similarly, the values of other cultivation showed different species diversity index for each group.This agrees with those of Jiang et al. (2015) who indicated that the application of organic materials tended to increase the number of individuals in the soil fauna.

According to Simpson Index, which reflected the measure of dominance, it was found that the organic marigold recorded the lowest number of dominant species. The results are similar to those reported by Jiang et al. (2015) who stated that the highest H' and $\mathrm{J}$ of soil fauna were for the organic manure treatment with averages of 2.73 and 0.59 , respectively.

\section{Similarity of species}

Community of collected mites from both conventional chamomile and marigold were lower than those collected from both organic ones as recorded respectively (309\& 224 individuals for conventional) and (484\&449individuals for organic). The number of mite species in organic marigold was higher (30 species) than those in conventional one (17 species); otherwise, those numbers were subequal in both organic and conventional chamomile (20 \& 22species, respectively).

According to Sørensen's quotient, it was concluded that the similarity to conventional compared by organic recorded 0.5 in chamomile and 0.5106 in marigold. Thus, the community of organicalmost resembles that of conventionalby $50 \%$ in chamomile and $51.06 \%$ in marigold.

This is consistent with the findings of Minor and Norton (2004), who found that compost, had a greater effect on mite diversity than chemical fertilizer, although both treatments reduced the diversity.

\section{REFERENCES}

Abo-Shnaf, Reham I. A.; Zaki, A. Y.; Aly, A. I. and Mergawy, M. M. 2016. Effect of different fertilization treatments on the biodiversity of mites associated with tomato plants and its yield in Fayoum governorate, Egypt. Acarines, 10: 25-29.

Altieri, M. A. and Nicholls, C. I. 2003. Soil fertility management and insect pests: harmonizing soil and plant health in agroecosystems. Soil \& Tillage Research, 72: 203-211.

Anonymous 2016. Bulletin of the Agricultural Statistics. Economic Affairs Sector, Ministry of Agriculture and Land Reclamation, Egypt.

Arora, D.; Rani, A. and Sharma, A. 2013. A review on phytochemistry and ethnopharmacological aspects of genus Calendula. Pharmacogn. Rev., 
7 (14): 179-187.

Behan-Pelletier, V. M. 1999. Oribatid mite biodiversity in agro ecosystems: role for bio indication. Agric. Ecosyst. Environ., 74: 411-423.

Bünemann, E. K.; Schwenke,G. D. and Van Zwieten, L. 2006. Impact of agricultural inputs on soil organisms-a review. Aust. J. Soil Res., 44: 379-406.

Crowder, D. W.; Northfield, T. D.; Strand, M. and Snyder, W. E. 2010. Organic agriculture promotes evenness and natural pest control. Nature, 46: 109-112.

Hutton, S. A. and Giller, P. S. 2003. The effects of the intensifications of agriculture on northern temperate dung beetle communities. J. Appl. Ecol., 40: 994-1007.

Jiang, M.; Wang, X.; Liusui, Y.;Sun, X.; Zhao, C. and Liu, H. 2015. Diversity and Abundance of Soil Animals as Influenced by Long-Term Fertilization in Grey Desert Soil, China. Sustainability, 7: 10837-10853. doi: 10.3390/su70810837

Klingen, I.; Eilenberg J. and Meadow R. 2002. Effects of farming system, field margins and bait insect on the occurence of insect pathogenic fungi in soils. Agric. Ecosyst. Environ., 91: 191-198.

Lal, R. K.; Sharma, J. R.; Misra, H. O. and Singh, S. P. 1993. Induced floral mutants and their productivity in German chamomile (Matricaria recutita). Indian J. Agric. Sci., 63: 27-33.

Lampkin, N. 1990. Organic Farming. Farming Press Books, Ipswich, $701 \mathrm{pp}$.

Ludwig, J. A. and Reynolds, J. F. 1988. Statistical Ecology: A primary methods and computing. New York. 337pp.

Minor, M. A. and Cianciolo, J. M. 2007. Diversity of soil mites (Acari: Oribatida, Mesostigmata) along a gradient of LUTs in New York. Appl. Soil Ecol., 35: 140-153.

Paoletti, M. G.; Pimental, D.; Stinner, B. R. and Stinner. D. 1992. Agroecosystem biodiversity: matching production and conservation biology. Agric. Ecosyst. Environ., 40: 3-23.

Raey, Y. and Alami-Milani, M. 2014. Organic cultivation of medicinal plants: a review. J. Biodiv. Environ. Sci., (JBES), 4 (4): 6-18.

Rizk, M. A. 2015. What is sustainable agriculture development? Egypt, J. Agric. Res., 93 (1) (c): 915-920.

Siegrist, S.; Schaub, D.; Pfiffner, L. and Mader, P. 1998. Does organic agriculture reduce soil erodibility? The results of a longterm field study on loess in Switzerland. Agric. Ecosyst. Environ., 69: 253-265.

Singh, O.; Khanam, Z.; Misra, N. and Srivastava, M. K. 2011. Chamomile (Matricaria chamomilla L.): An overview. Pharmacogn. Rev., 5 (9): 82-95.

Sørensen, T. 1948. A method of establishing groups of equal amplitude in plant sociology based on similarity of species and its application to analyses of the vegetation on Danish commons. Biologiske Skrifter / Kongelige Danske Videnskabernes Selskab, 5 (4): 1-34.

Zehnder, G.; Gurr, G. M.; Kühne, S.; Wade, M. R.; Wratten, S. D. and Wyss, E. 2007. Arthropod pest management in organic crops. Ann. Rev. Entomol., 52: 57-80.

Zhiping, C.; Han, X.; Hu, C.; Chen, J.; Zhang, D. and Yosef, S. 2011. Changes in the abundance and structure of a soil mite (Acari) community under long-term organic and chemical fertilizer treatments. Appl. Soil Ecol., 49: 131-138. 